\title{
Mathematical Morphology on MRI for the Determination of Iberian Ham Fat Content
}

\author{
Andrés Caro ${ }^{1}$, Marisa Durán ${ }^{1}$, Pablo G. Rodríguez ${ }^{1}$, Teresa Antequera ${ }^{2}$, \\ and Ramón Palacios ${ }^{3}$
}

\begin{abstract}
${ }^{1}$ Dpto. Informática, Escuela Politécnica, Univ. Extremadura, 10071 Cáceres andresc@unex.es, mlduran@unex.es, pablogr@unex.es http: / / webepcc. unex.es/pablogr/jamon.html
\end{abstract}

${ }^{2}$ Tecnología de los Alimentos, Facultad de Veterinaria, Univ. Extremadura, 10071 Cáceres tantero@unex.es

3 Servicio de Radiodiagnóstico, Hospital Universitario Infanta Cristina, Badajoz

\begin{abstract}
Intermuscular Fat Content and its distribution during the ripening process of the Iberian ham is a relevant task from the point of view of technological interest. This paper attempts to study the Iberian ham during the ripening process with images obtained from a MRI (Magnetic Resonance Imaging) device using Pattern Recognition and Image Analysis algorithms, in particular Mathematical Morphology techniques. The main advantage of this method is the non-destructive nature. A concrete algorithm is proposed, which is based on the Watershed transformation. In addition, the results are compared with the Otsu thresholding algorithm. The decreases of the total volume in the ripening process are shown. Also the decrease of the meat percentage and intermuscular fat content are calculated. As a conclusion, the viability of these techniques is proved for the possible future utilization in the meat industries to discover new characteristics in the ripening process.
\end{abstract}

\section{Introduction}

Image classification by segmentation is a very important aspect of the Computer Vision techniques. It is being applied in the field of Food Technology to determine some features of this kind of images, as for example the quantification and distribution of intermuscular fat content in the Iberian ham. In our study, these results will be computed attempting to improve the industrial process, since fat content and its distribution influences water loss and salt diffusion during the ripening process [1].

Iberian ham images have been processed in this research in order to find out some characteristics and reach conclusions about this excellent product. The Iberian pig is a native animal bred from the south-western area of Spain, and dry-cured ham from Iberian pig is a meat product with a high sensorial quality and first-rate consumer acceptance in our country. The ripening of Iberian ham is a long process (normally 1824 months). Physical-chemical and sensorial methods are required to evaluate the different parameters in relation with quality, being generally tedious, destructive and 
expensive [1]. Traditionally, the maturation time is fixed, when the weight loss of the ham is approximately $30 \%$ [2]. So, other methodologies have long been awaited by the Iberian ham industries.

The use of image processing to analyze Iberian products is quite recent. Some researches have processed flat images taken by a CCD camera from Iberian ham slices for different purposes $[3,4,5]$. They estimated some parameters in Iberian ham like intramuscular fat content [5] and marbling [3] or classified various types of raw Iberian ham [4]. The obtained results were very encouraged and suggestive to its application for the systematic inspection of Iberian products. However, although Computer Vision is essentially a non-destroying technique, ham pieces must be destroyed to obtain images using these techniques.

MRI (Magnetic Resonance Imaging) offers great capabilities to non-invasively look inside the bodies. It is widely used in medical diagnosis and surgery. It provides multiple planes (digital images) of the body or piece. Its application to the Food Technology is still recent and it is confined for researching purposes. Cernadas et al. [6, 7, 8] analyze MRI images of raw and cured Iberian loin to classify genetic varieties of Iberian pigs and to predict the intramuscular fat content [9]. The results are promising to its application to ham [10]. The loin is an uniform and simple muscle, and this is a very important advantage, comparing with the great number and complex distribution of muscles of the ham, being this one a significant drawback.

The image segmentation can be realized via the Mathematical Morphology methods. These techniques detect object structures or forms in images. A special method of segmentation is the Watershed Transformation, which is based on Mathematical Morphology $[11,12,13]$. In our paper, the Watershed Segmentation will be applied to characterize the quantification and distribution of the fat content in Iberian hams. The results of this last technique will be tested by a well-known segmentation method based on Otsu thresholding [14]. A comparative study between these two techniques is realized to analyze three regions in images (background, intermuscular fat content and meat).

This method is applied over a database of specific MR images from Food Technology, particularly Iberian ham images obtained at three different maturation stages (raw, semi-cured and dry-cured Iberian ham). Mathematical Morphology is used to achieve the quantification and distribution of intermuscular fat content in the total Iberian ham, studying its volume changes during the ripening process of the Iberian ham. The verification of the presented approach is shown examining these changes, and the obtained practical results may allow us to optimize time, temperature and salt content during ripening of Iberian ham.

\section{Data Set}

The presented research is based on MRI sequences of Iberian ham images. Its application to Food Technology is still recent and it is confined for researching purposes. Four Iberian hams have been scanned, in three stages during their ripening time. The images have been acquired using an MRI scan facilitated by the "Infanta Cristina" 
Hospital in Badajoz (Spain). The MRI volume data set is obtained from sequences of T1 images with a FOV (field-of view) of 120x85 mm and a slice thickness of $2 \mathrm{~mm}$, i.e. a voxel resolution of $0.23 \times 0.20 \times 2 \mathrm{~mm}$. The total number of images in the obtained database is 252 .

\section{Classification Methods}

Watershed transformation is used to classify different tissues in images of Iberian hams (based on regions), in comparison with thresholding segmentation Otsu method (based on pixels).

\subsection{Thresolding: Otsu Method}

Otsu method is a widely used thresholding segmentation technique, which can be employed for classification of tissues. Concretely, Otsu and multi-level Otsu methods minimize the weighted sum of group variances: let $\sigma_{w}^{2}, \sigma_{B}^{2}$ and $\sigma_{T}^{2}$ be the withinclass, between-class variance, and the total variance, respectively [14]. An optimal threshold, $t$, can be determined by maximizing one of the following criterion functions with respect to $t$ :

$$
\lambda=\frac{\sigma_{B}^{2}}{\sigma_{W}^{2}} \quad \eta=\frac{\sigma_{B}^{2}}{\sigma_{T}^{2}} \quad \kappa=\frac{\sigma_{T}^{2}}{\sigma_{W}^{2}}
$$

The Otsu segmentation method in Iberian ham for intramuscular fat content has been perfectly evaluated, in comparison with the chemical analyses that are realized habitually on this kind of meat [15].

\subsection{Mathematical Morphology: Watershed Segmentation}

The Watershed transformation segments images into watershed regions [10]. Considering the gray scale image as a surface, each local minimum can be thought of as the point to which water falling on the surrounding drainage regions (figure 1).

Noise and small unimportant fluctuations in the original image can produce spurious minima, which leads to oversegmentation. Smoothing the original image is an approach to overcoming this problem.

We have used the Watershed Transformation to classify three different regions in Iberian ham images from MRI (background, meat and fat).

Figure 2 shows images from the proposed algorithm. Different regions can be appreciated in the Watershed images, and the classification in three categories.

The algorithm works over our database with original images (figure 2.A shows one these images). This image is filtered by a Morphological Closing algorithm, using 
as structural element a disk with a radio of 5 pixels (figure 2.B). A median filter is used with a window size of $5 \times 5$ pixels. Next step consists on using a Sobel operator in order to detect boundaries, in which Watershed regions could be placed. The output image is converted to a binary image (bilevel image) and a median filter is applied again. All these steps (median filter, Sobel operator, binarization and median filter again) are necessary to avoid the oversegmentation of the regions with the Watershed Transformation.

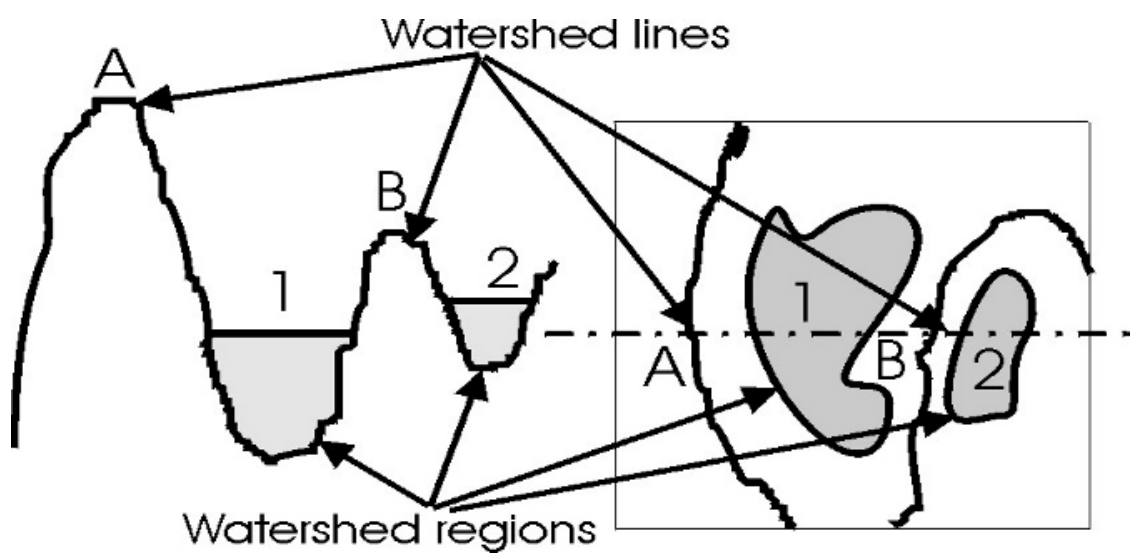

Fig. 1. Intuitive definition of the Watershed Transformation (Watershed regions: 1 and 2; Watershed lines: A and B).

When the image is correctly pre-processed the Watershed Transformation is applied, obtaining different interesting images. One of them is the figure 2.C, which shows Watershed regions. They are classified with the average gray level of the same regions over the original image. Another interesting image is the figure 2.D, with the original image mixed with the Watershed regions. Figure 2.E illustrates the final multi-level Otsu classification in three gray levels. Finally, the figure 2.F is the classification of the Watershed regions. They have been obtained by the proposed algorithm, which can be easily compared in the original image (2.A) and in the Otsu classification (2.E). The numerical results as well as the comparison of both methods are shown in the following sections. 


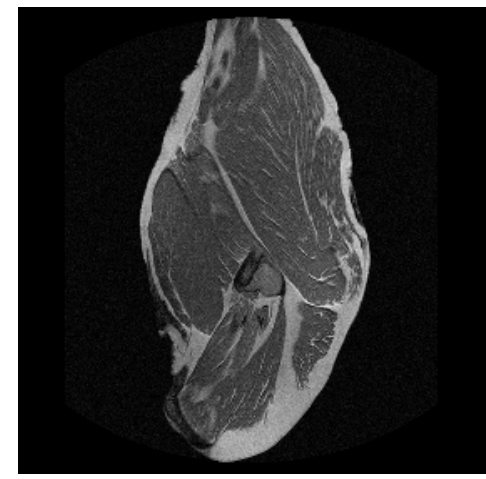

A)

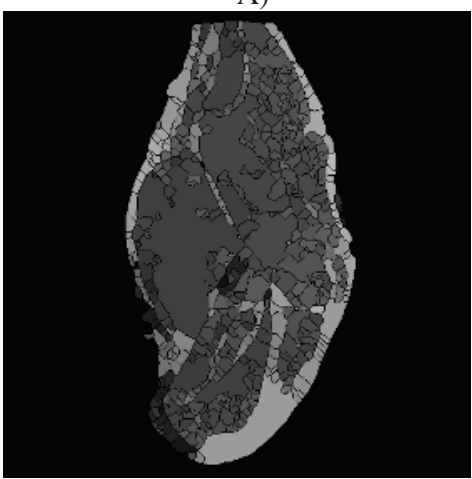

C)

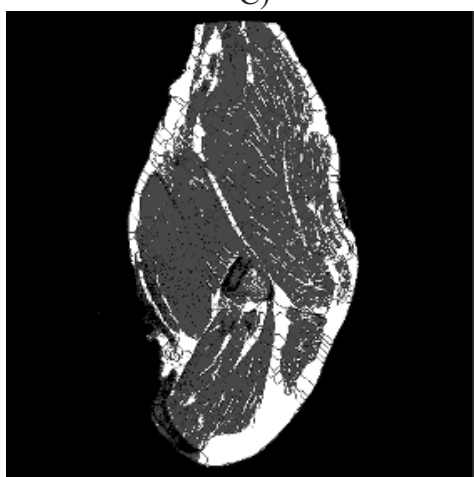

E)

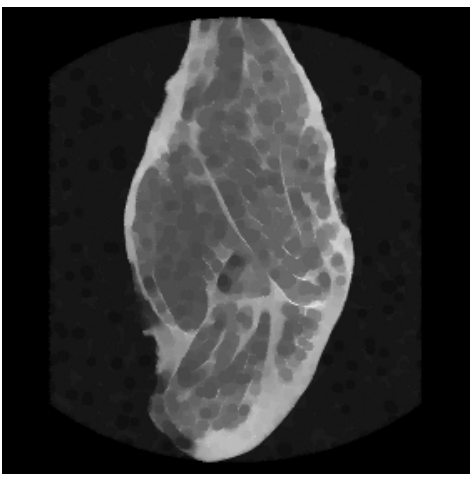

B)

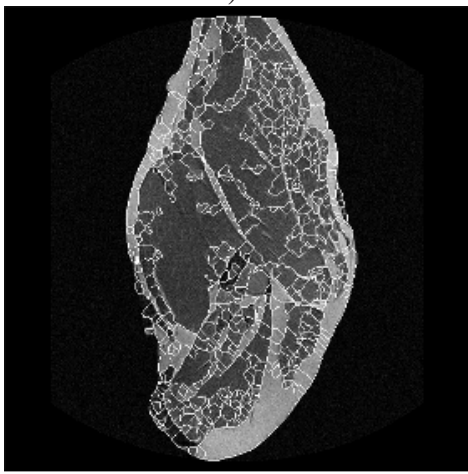

D)

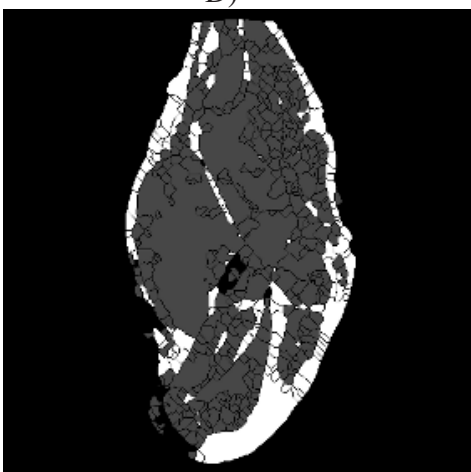

F)

Fig. 2. Example images. A) Original image. B) Morphological closing. C) Watershed regions with the average of gray levels for each area. D) Binarization of the image with the watershed regions. E) Classification in three regions by thresholding with the Otsu method. F) Classification in three regions by the Watershed transformation. 


\section{Results}

Four bar charts show the obtained results with the two tested algorithms. Three stages have been considered (MR images acquired) in the ripening process: raw, semi-dry and dry-cured ham.

The total volume decrease in the ripening process of the Iberian ham can be observed in the figure 3. The total absolute reduction is shown in figure 3.A, with the average of the four considered hams of this study. The comparative studies between both techniques (Watershed and Otsu) are quite similar. For example, the first bar of the graph shows values near 80.000 pixels in both cases. The percentage reduction has been $15-20 \%$ in average, from the initial to the final stage (figure 3.B).

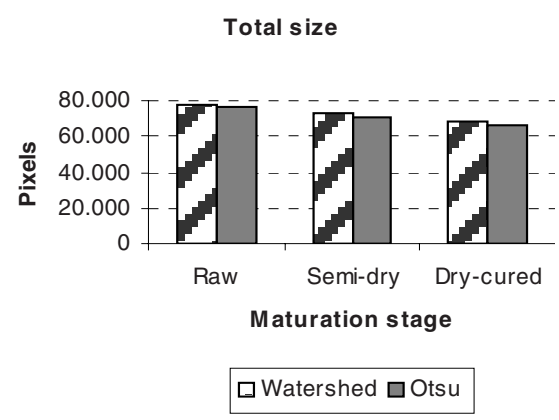

(A)

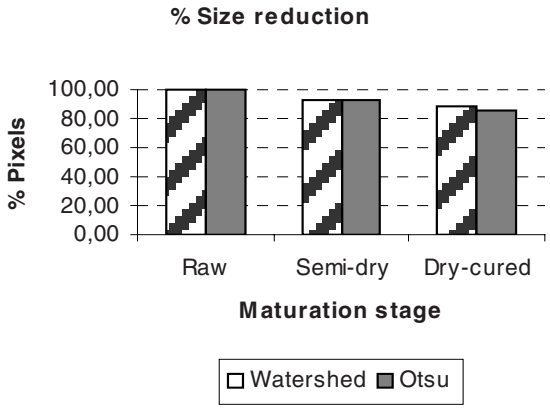

(B)

Fig. 3. Total size reduction, in absolute (A) and relative (B) values.

Figure 4 shows the percentage size of the fat (4.A) and meat (4.B) content as an average of the four hams (relative quantity in relation to the number of pixels in the ham area). The results are similar in the Watershed and Otsu segmentation as well.

In addition, as it was waited, the total size of the ham decreases; however, the relative quantity of fat content keeps more or less constant.

\section{Discussion and Conclusions}

The results obtained using both computer vision techniques are quite similar to the quantities calculated by the Food Technology specialists. They have estimated the total weight decrease at $30 \%$ in the Iberian ham during the same time. The proposed algorithm obtains a reduction of the ham size of about $15-20 \%$ approximately, in all the processed images. Therefore, a relationship between the ham weight decrease $(30 \%)$ and total volume reduction $(15 \%)$ could be established for the maturation time, as a first approximation. This size reduction could be caused by the loss of water dur- 
ing the maturation process. Optimal ripening time could not be the same for different Iberian pig hams. By studying the percentage rate of volume during the process, it could be possible to predict the optimal ripening moment.

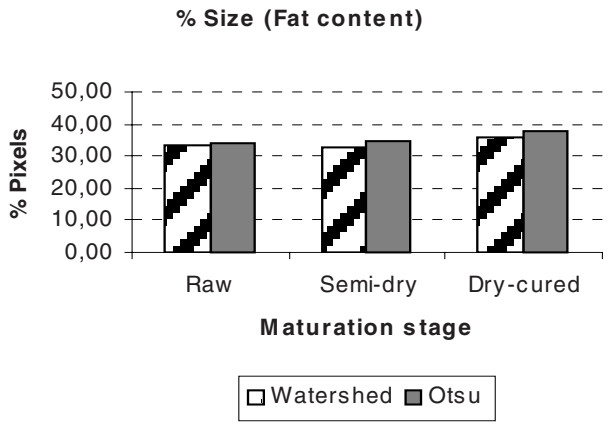

(A)

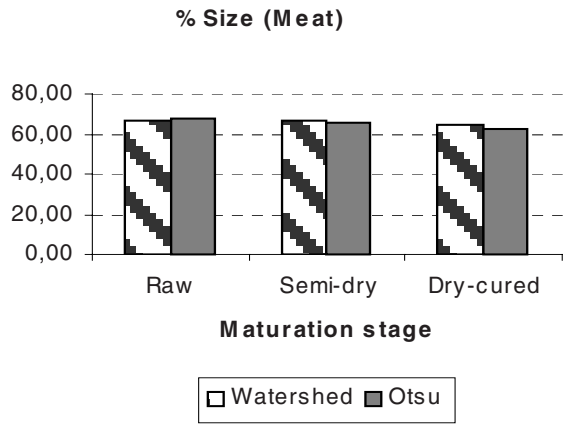

(B)

Fig. 4. Fat (A) and meat content (B), in percentage over the ham volume.

Discussing about both techniques, Otsu method could be considered a good way to evaluate the fat level, but it does not offer information about the distribution of fat, i.e. it is only a good quantification method. The classification process is realized pixel by pixel. Wrong pixel classifications could be achieved, for example when noisy pixels appears on the image.

On the other hand, Watershed transform classifies full regions into the selected class. This method catalogs the whole region (all the pixels of the watershed region) into the adequate category. Therefore, not only quantitative information is achieved by this method, but also its distribution inside of the image, which is quite important too.

The main aim of this paper is the quantification and distribution of the intermuscular and subcutaneous fat content. The selected method to this classification is Watershed Transformation, due to the fact that it not only computes the quantity of fat, but in addition the regions of fat content are perfectly located.

Acknowledgments. The authors are grateful to the Denominación de Origen "Dehesa de Extremadura" and the Hermanos Alonso Roa company from Villar del Rey (Badajoz). In addition, we wish to express our gratitude to the Department of Systèmes Logiques et Numériques in the University Libre de Bruxelles (Belgium). This work has been supported by Junta de Extremadura (Local Government), under the IPR98A03P and the 2PR01C025 projects. 


\section{References}

1. Antequera, T., López-Bote, C.J., Córdoba, J.J., García, C., Asensio, M.A., Ventanas, J. and Díaz, Y., "Lipid oxidative changes in the processing of Iberian pig hams", Fod. Chem., 54, 105, 1992.

2. Cava, R. and Ventanas, J., "Dinámica y control del proceso de secado del jamón ibérico en condiciones naturales y cámaras climatizadas", Tecnología del jamón ibérico, Ed. Mundi Prensa, 260-274, 2001.

3. Cernadas, E., Durán, M.L., Antequera, T., "Recognizing Marbling in Dry-Cured Iberian Ham by Multiscale Analysis". Pattern Recognition Letters, 23, pp.1311-1321, 2002.

4. Durán, M. L., Cernadas, E., Caro, A., Antequera, T., "Clasificación de distintos tipos de jamón ibérico utilizando Análisis de Texturas", Revista Elec. Visión por Comp., № 5, 2001.

5. Durán, M. L., Caro, A., Cernadas, E., Plaza, A., Petrón, M. J., “A fuzzy schema to evaluate fat content in iberian pig meat images”, Ibero-American Symp. Patt. Recog., 207-216, 2000 .

6. Cernadas, E., Durán, M.L., Rodríguez, P.G., Caro, A., Muriel, E. and Palacios, R., "Estimating intramuscular fat content of cured Iberian loin using statistical analysis of its magnetic resonance images", $12^{\text {th }}$ Portuguese Conference on Pattern Recognition, 2002.

7. Cernadas, E., Plaza, A., Rodríguez, P.G., Durán, M.L., Hernández, J., Antequera, T., Gallardo, R. y Villa, D., "Estimation of Dry-Cured Iberian Ham Quality Using Magnetic Resonance Imaging", $5^{\text {th }}$ Int. Conf. Applic. Mag. Resonance in Food Science, pp.46-47, 2000 .

8. Cernadas, E., Antequera, T., Rodríguez, P.G., Durán, M.L., Gallardo, R. y Villa, D., "Magnetic Resonance Imaging to Classify Loin from Iberian Pigs", Mag. Resonance in Food Science, pp. 239-254. Ed. The Royal Society of Chemistry, 2001.

9. Antequera, T., Muriel, E., Rodríguez, P.G., Cernadas, E., Ruiz J., "Magnetic Resonance Imaging as a Predictive Tool for Sensoring Characteristic and Intramuscular Fat Content of Dry-Cured Loin". Int. Journal of Science and Food and Agric., Vol.83, pp. 268-274, 2003.

10. Caro, A., Rodríguez, P.G., Cernadas, E., Antequera, T., "Disminución volumétrica del jamón ibérico durante su maduración analizando imágenes de Resonancia Magnética mediante Contornos Activos", Revista "Información Tecnológica” Vol. 13 No 3, pp. 175180, 2002.

11. Beucher, S. and Meyer, F., "The Morphological Approach to Segmentation: The Watershed Transformation", Math. Morphology in Image Processing, pp. 433-482, E.R. Dougherty, ed., New York, Basel, Hong Kong: Marchel Dekker, 1993.

12. Serra, J. "Image Analysis and Mathematical Morphology", Academic Press, New York. 1982

13. Caro, A., Rodríguez, P.G., Ávila, M., Rodríguez, F., Rodríguez, F.J., "Active Contours Using Watershed Segmentation", $9^{\text {th }}$ Int. Workshop on Systems, Signal and Image Processing, pp. 340-345, Manchester (UK), 7-8 November 2002.

14. Otsu, N., "A Threshold Selection Method from Gray-Level Histograms", IEEE Trans. Systems, Man, and Cybernetics, Vol. SMC-9, No. 1, Jan 1979.

15. Durán, M.L., Cernadas, E., Plaza, A., Sánchez, J.M., Rodríguez, F., Petrón, M.J., "Could Machine Vision Replace Chemical Procedure to Evaluate Fat Content in Iberian Pig Meat? An Experimental Study", $3^{\text {rd }}$ Int. Conf. on Computer Vision, Pattern Recognition, and Image Processing, pp. 256-259, Atlantic City, New Jersey (USA), 2000. 